\title{
Neural tube defect recurrence after 'partial' vitamin supplementation
}

\author{
SHEILA SHEPPARD, N C NEVIN, MARY J SELLER, JENNIFER WILD, \\ $R$ W SMITHELLS, A P READ, R HARRIS, D W FIELDING,
} AND C J SCHORAH

From the Departments of Paediatrics and Child Health, and Chemical Pathology, University of Leeds; Department of Medical Genetics, Queen's University of Belfast; Paediatric Research Unit, Guy's Hospital, London; Department of Medical Genetics, University of Manchester; and Department of Paediatrics, The Countess of Chester Hospital, Chester.

SUMmARY A total of 227 mothers enrolled for periconceptional multivitamin supplementation

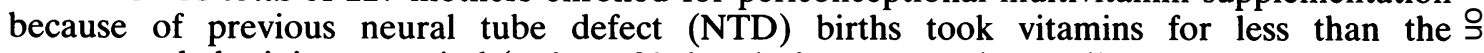
recommended minimum period (at least 28 days before conception until two menstrual periods have been missed). Of 213 examined infants/fetuses born to these partially supplemented mothers, two had NTD, one of whom followed four previous NTDs. The observed NTD recurrence rate is similar to that observed in fully supplemented mothers. A further 14 mothers started supplements before the second missed period but after the normal time of neural tube closure. Three of their offspring had NTD. The significance of this apparently high recurrence rate is discussed.

We have previously reported a reduced rate of neural tube defect (NTD) recurrence in the offspring of mothers who received periconceptional vitamin supplementation with Pregnavite Forte $\mathrm{F}^{*}{ }^{12}$ Fully supplemented (FS) mothers are defined as those who took vitamin supplements for at least 28 days before conception and continued taking them until the date of the second missed menstrual period. Mothers who omitted supplements on any one day during this defined period were also classified as FS. Mothers whose duration of supplementation was shorter were classified as partially supplemented (PS). Previous publications have concentrated on pregnancy outcome in FS mothers. ${ }^{12}$ (Some authors have criticised these publications because our subjects were not randomised ${ }^{3}$ and we have responded to these criticisms. ${ }^{4}$ ) We now present in detail additional data on pregnancy outcome in PS mothers as part of the ongoing debate on vitamin supplementation.

\footnotetext{
*Bencard. 1 tablet three times a day, which provides daily vitamin A $4000 \mathrm{IU}$, vitamin D $400 \mathrm{IU}$, thiamine $1.5 \mathrm{mg}$, riboflavin $1.5 \mathrm{mg}$, pyridoxine $1 \mathrm{mg}$, nicotinamide $15 \mathrm{mg}$, ascorbic acid $40 \mathrm{mg}$, folic acid $0.36 \mathrm{mg}$, ferrous sulphate equivalent to $75.6 \mathrm{mg} \mathrm{Fe}$, and calcium phosphate $480 \mathrm{mg}$.

Received for publication 30 April 1988.

Revised version accepted for publication 18 October 1988
}

\section{Patients and methods}

Full details of our protocol have been published previously. ${ }^{12}$ All mothers recruited to the study have had one or more NTD infants/fetuses. Pregnancy outcome was known for 114 PS mothers at the time of our last report, ${ }^{2}$ since when an additional 113 PS mothers have been delivered. A further group of 14 mothers who started taking vitamins after the calculated date of neural tube closure (late supplementation) will be considered separately.

\section{Results}

The pattern of vitamin supplementation in PS mothers is variable. Supplementation was in- 0 complete in some before conception, in some after $\mathrm{\omega}$ conception, and in others both before and after. ${ }^{\circ}$ Table 1 shows pregnancy outcome with regard to 0 NTD according to supplementation pattern and $\overparen{\varnothing}$ number of previous NTDs. The majority of PS $\stackrel{\oplus}{-}$ mothers conceived less than 28 days after starting $\frac{T}{T}$ supplements, but were fully supplemented after conception. Of 112 infants/fetuses born to mothers $\cong$ in this group with a history of one previous NTD, $\stackrel{\unrhd}{\unrhd}$ eight spontaneously aborted fetuses were not $\bar{Q}$ examined. There were no NTDs among the other 
TABLE 1 Outcome of pregnancy in 227 partially supplemented mothers by number of previous NTDs and supplementation history.

\begin{tabular}{|c|c|c|c|c|c|c|c|c|c|c|c|c|}
\hline \multirow{3}{*}{$\begin{array}{l}\text { Postconception } \\
\text { supplementation }\end{array}$} & \multicolumn{12}{|c|}{ Preconception supplementation } \\
\hline & \multicolumn{3}{|c|}{ Complete } & \multicolumn{3}{|c|}{ Incomplete } & \multicolumn{3}{|l|}{ None } & \multicolumn{3}{|l|}{ Total } \\
\hline & $\begin{array}{l}\text { Not } \\
\text { NTD }\end{array}$ & $N T D$ & $N / E$ & $\begin{array}{l}\text { Not } \\
\text { NTD }\end{array}$ & $N T D$ & $N / E$ & $\begin{array}{l}\text { Not } \\
\text { NTD }\end{array}$ & $N T D$ & $N / E$ & $\begin{array}{l}\text { Not } \\
\text { NTD }\end{array}$ & $N T D$ & $N / E$ \\
\hline \multicolumn{13}{|l|}{1 Previous NTD } \\
\hline Complete & \multicolumn{3}{|c|}{ Fully supplemented } & $94^{* * *}$ & 0 & 7 & 10 & 0 & 1 & $104^{* * *}$ & 0 & 8 \\
\hline Incomplete & 16 & 0 & 2 & 13 & 1 & 1 & 62 & 0 & $7^{*}$ & 91 & 1 & $10^{*}$ \\
\hline \multicolumn{13}{|l|}{$\geq 2$ previous NTDs } \\
\hline Complete & \multicolumn{3}{|c|}{ Fully supplemented } & 10 & $1+$ & 0 & 1 & 0 & 0 & 11 & $1+$ & 0 \\
\hline Incomplete & 1 & 0 & 0 & 1 & 0 & 0 & 3 & 0 & 0 & 5 & 0 & 0 \\
\hline Total & 17 & 0 & 2 & $118^{* * *}$ & 2 & 8 & 76 & 0 & $8^{*}$ & $211^{* * *}$ & 2 & $18^{*}$ \\
\hline
\end{tabular}

*Includes one co-twin.

tFour previous NTDs.

$\mathrm{N} / \mathrm{E}=$ unexamined spontaneous abortion.

104 infants/fetuses. The 12 infants/fetuses born to mothers in this group with a history of more than one previous NTD were all examined. There was one NTD recurrence to a mother with a history of four previous NTDs. She had started supplements seven days before conception and was fully supplemented after conception.

The second largest group of PS mothers comprises those who started supplementation after conception, but before the estimated date of final neural tube closure. Of 69 infants/fetuses born to mothers in this group after one NTD (seven unexamined abortuses) and three born to mothers after more than one NTD (all examined) none of the 65 examined had NTD.

Nineteen mothers, including one who had more than one previous NTD, had complete preconceptional but incomplete postconceptional supplementation. Of 17 infants/fetuses examined, none had NTD.

Sixteen mothers, one of whom had more than one previous NTD, had incomplete pre- and postconceptional supplementation. One abortus was not examined. Of 15 infants/fetuses examined, one had NTD. This mother, with a history of one previous NTD, took supplements for 18 days before conception and for 28 days after (by which time the neural tube is normally closed).

Overall, there was one NTD recurrence among 196 examined infants/fetuses born to PS mothers after one previous NTD and one recurrence (after four previous NTDs) among 17 examined infants/ fetuses born to PS mothers who had had more than one previous NTD, in total $2 / 213$ recurrences.

\section{LATE SUPPLEMENTATION}

Fourteen mothers, four of whom have been reported previously, ${ }^{2}$ started taking supplements before the date of the second missed period, but after the date of normal neural tube closure. This may occur if, at the time of initial contact with the mother, there is uncertainty about the precise stage

TABLE 2 Pregnancy outcome in women who started supplements at conception or later.

\begin{tabular}{|c|c|c|c|c|c|c|c|c|c|}
\hline \multirow{2}{*}{$\begin{array}{l}\text { Day } \\
\text { started }\end{array}$} & \multicolumn{3}{|c|}{1 previous NTD } & \multicolumn{3}{|c|}{$\geq 2$ previous $N T D$ s } & \multicolumn{3}{|l|}{ All } \\
\hline & $\begin{array}{l}\text { Not } \\
\text { NTD }\end{array}$ & $N T D$ & $N / E$ & $\begin{array}{l}\text { Not } \\
\text { NTD }\end{array}$ & $N T D$ & $N / E$ & $\begin{array}{l}\text { Not } \\
\text { NTD }\end{array}$ & $N T D$ & $N / E$ \\
\hline Conception & 10 & 0 & 1 & 1 & 0 & 0 & 11 & 0 & 1 \\
\hline $1-5$ & 14 & 0 & 1 & 0 & 0 & $\mathbf{0}$ & 14 & 0 & 1 \\
\hline $6-10$ & 15 & 0 & 1 & 0 & 0 & $\mathbf{0}$ & 15 & 0 & 1 \\
\hline $11-15$ & 9 & 0 & $3^{*}$ & 0 & 0 & 0 & 9 & 0 & $3^{*}$ \\
\hline $16-20$ & 12 & 0 & 0 & 1 & 0 & 0 & 13 & 0 & 0 \\
\hline $21-25$ & 11 & 0 & 1 & 2 & 0 & 0 & 13 & 0 & 1 \\
\hline $\begin{array}{l}26 \\
\text { (presumed day of final neural } \\
\text { tube closure) }\end{array}$ & 0 & 0 & 1 & 0 & 0 & 0 & 0 & 0 & 1 \\
\hline $27-30$ & $5 \dagger$ & 0 & 1 & 1 & 0 & 0 & $6+$ & 0 & 1 \\
\hline $31-35$ & 2 & 3 & 0 & 1 & 0 & 0 & 3 & 3 & 0 \\
\hline 41 & 1 & 0 & 0 & 0 & 0 & 0 & 1 & 0 & 0 \\
\hline
\end{tabular}

Not tabulated: one mother supplemented days 4 to 10 (normal LB).

*Co-twin included.

†Includes two mothers given Pregnavite Forte F by their GPs.

$\mathrm{N} / \mathrm{E}=$ unexamined spontaneous abortion. 
of gestation, and a 'benefit of the doubt' decision is made. Two of the 14 mothers (one who had had a previous PS pregnancy and one who had earlier enrolled for supplementation, but then withdrawn because of constipation) had Pregnavite Forte $F$ prescribed by their general practitioners after they had missed a period. The other 12 mothers were excluded from the main study after estimations of gestational age by the obstetrician indicated that they had started supplements after the neural tube should have closed. The decision to exclude was made when neither the results of prenatal diagnostic tests for NTD nor the pregnancy outcome were known.

The outcome of pregnancy in this group of mothers is shown in table 2 , where it may be compared with that of the larger group of PS mothers who started vitamins at conception or up to day 26 postconception (the presumed day of final neural tube closure). There were no NTD recurrences among 76 examined infants/fetuses when supplements were started on or before day 26 . Among 13 for whom supplements were started on days 27 to 35 postconception, three had NTD: one spina bifida (vitamins started at 31 days), one encephalocele (34 days), and one anencephaly (35 days).

\section{Discussion}

When the periconceptional vitamin supplementation programme for the prevention of NTD was planned, the recommendation that vitamins be taken for at least 28 days before conception was based on an observed association between low maternal red blood cell (RBC) folate and NTD. ${ }^{5}$ Recently this association has been confirmed. ${ }^{6} \mathrm{RBC}$ folate levels cannot be increased very quickly, and 28 days represents a compromise between the time needed to achieve a maximal rise in $\mathrm{RBC}$ folate (about three months) and the time parents will postpone a pregnancy which they are keen to start.

The rationale for continuing vitamin supplements until the time of the second missed menstrual period (commonly 42 days after conception) was to ensure that they are taken until well past the time of normal neural tube closure (26 to 27 days).

Despite this advice, $17 \%$ of all mothers enrolled in the study did not fulfil these criteria for full supplementation. The reasons for this include: having conceived shortly before or about the time of enrolment; failure of contraceptive measures to protect; periods not having been re-established on a regular basis after a recent termination or after stopping the oral contraceptive pill; an unplanned pregnancy in a mother who had previously had a planned supplemented one; forgetting to take the vitamins for $>1$ day.

It is interesting to note that the NTD recurrence rate in these partially supplemented mothers (two of $213,0.94 \%$ ) is similar to that seen in fully supplemented mothers. At the time of our last publication $^{2}$ the rate in FS mothers was $0.7 \%$ (three of 429). In the period during which the 213 PS mothers have been studied, 1107 mothers have been fully supplemented, of whom 14 have had NTD recurrences $(1.26 \%$, table 3$)$. Thus it may be that the full supplementation regimen we originally proposed is not, in fact, strictly necessary: rather, a shorter period of therapy may suffice. This is of immense practical importance for the prevention of NTD, because the shorter the period of supplementation advised, the more people are likely to comply. As yet, our numbers of PS women are small, and more are required, for it is only from such women that the minimum effective duration of supplementation can be derived.

Our findings in mothers who started vitamin supplements after the estimated date of neural tube closure, and who are therefore effectively unsupplemented, are unexpected and of particular interest although, being few in number, their experiences must be interpreted with great caution.

Three NTD recurrences were seen among 13 infants/fetuses, supplements having been started on estimated days 31,34 , and 35 after conception (table 2 ), which contrasts very strikingly with the low recurrence rate $(2 / 211)$ in PS mothers starting supplements before the date of neural tube closure (table 1).

TABLE 3 Outcome of pregnancy in fully supplemented (FS) and partially supplemented (PS) mothers by number of previous NTDs.

\begin{tabular}{|c|c|c|c|c|c|c|c|c|c|}
\hline & \multicolumn{3}{|l|}{$F S$} & \multicolumn{3}{|l|}{$P S$} & \multicolumn{3}{|l|}{ Total } \\
\hline & $\begin{array}{l}\text { Not } \\
\text { NTD }\end{array}$ & $N T D$ & $\begin{array}{l}\text { Recurrence } \\
\text { rate }(\%)\end{array}$ & $\begin{array}{l}\text { Not } \\
\text { NTD }\end{array}$ & $N T D$ & $\begin{array}{l}\text { Recurrence } \\
\text { rate }(\%)\end{array}$ & $\begin{array}{l}\text { Not } \\
\text { NTD }\end{array}$ & $N T D$ & $\begin{array}{l}\text { Recurrence } \\
\text { rate }(\%)\end{array}$ \\
\hline $\begin{array}{l}1 \text { previous NTD } \\
>1 \text { previous NTD } \\
\text { Total }\end{array}$ & $\begin{array}{c}1005 \\
88 \\
1093\end{array}$ & $\begin{array}{r}10 \\
4 \\
14\end{array}$ & $\begin{array}{l}0 \cdot 99 \\
4 \cdot 34 \\
1 \cdot 26\end{array}$ & $\begin{array}{r}195 \\
16 \\
211\end{array}$ & $\begin{array}{l}1 \\
1 \\
2\end{array}$ & $\begin{array}{l}0.51 \\
5 \cdot 88 \\
0.94\end{array}$ & $\begin{array}{r}1200 \\
104 \\
1304\end{array}$ & $\begin{array}{r}11 \\
5 \\
16\end{array}$ & $\begin{array}{l}0 \cdot 91 \\
4 \cdot 59 \\
1 \cdot 21\end{array}$ \\
\hline
\end{tabular}


There are at least two potential errors in the calculation of dates. First, the estimated date of conception can at best be accurate within a day or two, and in this group the menstrual history was often unclear. Second, although the neural tube is normally completed by closure of the posterior neuropore on day 26 to 27 of embryonic life, it seems possible (as a hypothesis) that the process of closure might be slowed down in neural tubes destined not to close and that an intervention on day 28 (though probably not later) might be potentially effective.

Even with such small numbers, these results strongly suggest that vitamin supplementation begun after the neural tube should have closed cannot prevent NTD. The earliest start of vitamin supplements associated with NTD in later starters was at $\mathbf{3 1}$ days after conception, and the defect was spina bifida. Even if the hypothesis of delayed closure is valid, the speed of events in the fourth week of embryonic life is such that it seems improbable that supplements started as late as day 31 could influence neural tube closure. This must be even more true of anencephaly associated with supplements started on day 35 . Precise embryonic dating of encephalocele is more difficult to determine.

The data on late starters must not be taken as suggesting that Pregnavite Forte F might be teratogenic between days 30 and 35 . It is important to remember that all women counted as fully supplemented according to our protocol took Pregnavite Forte $F$ on days 30 to 35 , and we have documented the low risk of NTD in their offspring. ${ }^{12}$ It seems highly improbable that starting supplementation at day 30 to 35 could increase the risk of NTD, though obviously it would be prudent to pay particular attention to following up any pregnancy in which this happens.

These results lead to three conclusions. (1) Supplementation with Pregnavite Forte $F$ for prevention of NTD recurrences may be as effective if started at, or soon after, conception as when it is started before. (2) Supplements started 30 or more days after conception have no protective effect against NTD. (3) Particularly careful attention must be paid to pregnancy outcomes when vitamin supplements are started around the time of neural tube closure.

Periconceptional vitamin supplementation continues to be associated with a low rate of NTD recurrence. Whether the association is causal has yet to be proven. Studies in progress, including that of the Medical Research Council, may help to resolve the issue. Meanwhile, the UK Committee on Safety of Medicines has licensed Pregnative Forte $F$ for the prevention of NTD recurrences, and the product can be prescribed for this purpose under the British National Health Service.

We thank the mothers who took part in the study and the doctors who assisted in their recruitment; Miss Wendy P Johnston, Mrs Monica Elson, and Mrs Gwyn Lauterberg (Health Visitors); and Mrs Eileen Wood for preparing the manuscript. The work was supported by Action Research for the Crippled Child (RWS), the Buttle Trust (MJS), the Liverpool Children's Fund (MJS), the Northern Ireland Association for Spina Bifida and Hydrocephalus and branches (NCN), the Spastics Society (MJS), and Beecham Pharmaceuticals who supplied Pregnavite Forte F.

\footnotetext{
References

${ }^{1}$ Smithells RW, Sheppard S, Schorah CJ, et al. Apparent prevention of neural tube defects by periconceptional vitamin supplementation. Arch Dis Child 1981;56:911-8.

2 Smithells RW, Nevin NC, Seller MJ, et al. Further experience of vitamin supplementation for prevention of neural tube defect recurrences. Lancet 1983;i:1027-31.

3 Wald NJ, Polani PE. Neural-tube defects and vitamins: the need for a randomized clinical trial. Br J Obstet Gynaecol 1984;91:516-23.

4 Smithells RW, Sheppard S, Wild J, et al. Neural tube defects and vitamins: the need for a randomized clinical trial. $B r J$ Obstet Gynaecol 1985;92:185-9.

5 Smithells RW, Sheppard S, Schorah CJ. Vitamin deficiencies and neural tube defects. Arch Dis Child 1976;51:944-50.

6 Yates JRW, Ferguson-Smith MA, Shenkin A, GuzmanRodriguez $\mathrm{R}$, White $\mathrm{M}$, Clark $\mathrm{BJ}$. Is disordered folate metabolism the basis for the genetic predisposition to neural tube defects? Clin Genet 1987;31:279-87.
}

Correspondence to $\operatorname{Dr} S$ Sheppard, Paediatric Research Unit, D Floor, Clarendon Wing, The General Infirmary, Belmont Grove, Leeds LS2 9NS. 